\title{
Apanhador (Não Tão) Só: acontecimento em rede e as afetações de uma ruptura de coerência expressiva
}

\author{
A (not so) lonely catcher: network events and a band's rupture of expressive
} coherence

\section{Beatriz Polivanov}

Professora adjunta do Departamento de Estudos Culturais e Mídia da Universidade Federal Fluminense (UFF). Docente do Programa de Pós-Graduação em Comunicação da mesma instituição. Doutora e mestre pelo mesmo programa. Atualmente atua como professora visitante na Universidade de McGill, em Montreal, no Departamento de Art History and Communication Studies. Líder do grupo de pesquisa MiDICom - Mídias Digitais, Identidade e Comunicação - da UFF, inscrito no diretório do CNPq.

\section{Ronaldo Henn}

Possui graduação em Comunicação Social - Habilitação em Jornalismo pela Universidade do Vale do Rio dos Sinos (1984), mestrado em Comunicação e Semiótica pela Pontifícia Universidade Católica de São Paulo (1994), doutorado em Comunicação e Semiótica pela Pontifícia Universidade Católica de São Paulo (2000) e pós-doutorado na Universidade Nova de Lisboa. Atualmente é professor adjunto da Universidade do Vale do Rio dos Sinos e atua como pesquisador no PPG em Ciências da Comunicação.

\section{Jonas Pilz}

Doutorando do Programa de Pós-Graduação em Comunicação da Universidade Federal Fluminense; bolsista CAPES.

\section{Beatriz Medeiros}

Doutoranda do Programa de Pós-Graduação em Comunicação da Universidade Federal Fluminense; bolsista CAPES. 


\section{RESUMO}

Após a banda Apanhador Só fazer o lançamento da sua canção "Linda, louca e livre", em agosto de 2017, Clara Corleone, ex-companheira de um dos integrantes do grupo, fez uma publicação em seu perfil pessoal no Facebook denunciando situações de abuso psicológico e violência física pelas quais teria passado ao longo do relacionamento. Ela teria sido motivada pela suposta associação que, naquele momento, a banda fazia com os movimentos feministas através da letra da canção. 0 texto ganhou visibilidade e gerou uma significativa rede de debates, com características do que se entende como ciberacontecimento, provocando uma ruptura na coerência expressiva do grupo, na sua construção e performance identitária. Analisam-se aqui as afetações decorrentes desse processo através de postagens da banda, em sua página no Facebook, em relação ao ocorrido, bem como comentários a elas. Conclui-se que, para além de um processo de gerenciamento de crise momentâneo, com cancelamento de shows e tentativa de retratação por parte da banda, o acontecimento gerou repercussões possivelmente indeléveis, como o surgimento de ex-fãs.

PALAVRAS-CHAVE: Apanhador Só; ruptura de coerência expressiva; ciberacontecimento; gerenciamento de crise.

\section{ABSTRACT}

In August 2017, the band Apanhador Só released a song whose lyrics allude to feminist references. Motived by this release, Clara Corleone, ex-companion of one of the group's members, posted on her personal profile on Facebook a text reporting situations of psychological abuse and physical violence that she claimed to have suffered during the relationship. The post gained visibility online, and led to a significant network of debates, with characteristics of what is understood here as a cyberevent, causing a rupture in the group's expressive coherence, their identity construction and performance. In this paper, we analyze the effects of such a process through posts made by the band on their Facebook fan page, in relation to what had occurred, as well as comments to them. We conclude that, more than just a momentary crisis management, which led to the cancellation of concerts and an attempt at "retraction" by the band, the event triggered possibly indelible repercussions, such as the emergence of "ex-fans".

KEYWORDS: Apanhador Só; expressive coherence rupture; cyberevent; crisis management.

\section{RESUMEN}

Después de la banda Apanhador Só hacer el lanzamiento de su canción "Linda, louca e livre", en agosto de 2017, Clara Corleone, ex pareja de uno de los integrantes del grupo, hizo una publicación en su perfil personal en Facebook denunciando situaciones de abuso psicológico y violencia física por las que habría pasado mientras la relación. Ella fue motivada por la supuesta asociación que, en ese momento, la banda hacía con movimientos feministas a través de la letra de la canción. El relato ganó visibilidad y generó una expresiva red de debates, con características de lo que se aprehende por ciberacontecimiento, provocando una ruptura en la coherencia expresiva de la banda, en su construcción e identidad. Se analizan aquí las afectaciones resultantes de este proceso

Dossiê A Música e suas Determinações Materiais - https://revistaecopos.eco.ufrj.br/

ISSN $2175-8689$ - v. 23, n. 1, 2020

DOI: 10.29146/eco-pos.v23i1.27551 
a través de posturas de la banda en su perfil en Facebook con relación a lo ocurrido, así como comentarios presentes en ellas. Se concluye que, además de un proceso de gestión de crisis momentánea, con cancelación de espectáculos y tentativa de retractación por parte de la banda, el acontecimiento generó repercusiones posiblemente indelebles, como el surgimiento de "ex fans".

PALABRAS CLAVE: Apanhador Só; ruptura de la coherencia expresiva; ciberacontecimiento; gestión de crisis.

\section{Introdução}

Às $14 \mathrm{~h} 33$ min de 16 de agosto, uma mulher publicou um texto de 142 linhas no Facebook sobre o relacionamento que teve com um músico da banda Apanhador Só - no relato dela, um homem desleal, que usava artimanhas psicológicas para oprimi-la e chegou a quebrar seu dedo durante uma discussão. Às 18h01min do dia seguinte, o grupo anuncia a suspensão de suas atividades por meio de um post na mesma rede social (Weber, 2017, online).

A mulher mencionada na coluna do principal periódico do Rio Grande do Sul é a atriz, escritora, produtora cultural e radialista porto-alegrense Clara Corleone ${ }^{5}$. Clara publicou em seu perfil no Facebook um texto ${ }^{6}$ em que relata as tensões, físicas e psicológicas, de seu relacionamento, terminado naquele momento há três anos, com o guitarrista da banda Apanhador Só, Felipe Zancanaro. 0 texto foi publicado pouco depois do lançamento, pelo grupo, da canção "Linda, louca e livre”, apontada por Clara como contraditória, já que o título, supostamente, faz referência a um lema utilizado com frequência em manifestações feministas latino-americanas ("ni sumisa ni devota, te quiero linda, libre y $\left(\operatorname{loca}^{\prime \prime}\right)^{7}$, enquanto um dos integrantes do trio teria comportamentos tidos como incoerentes com tal posicionamento político-ideológico.

\footnotetext{
${ }^{5}$ Clara Corleone tem graduação em Arte Dramática, apresenta o programa Todas as mulheres do mundo na webradio Rádio Elétrica e é hostess da tradicional casa noturna porto-alegrense Ocidente. Em seu perfil no Facebook, costuma publicar textos autorais e reflexivos sobre o seu cotidiano e impressões sobre acontecimentos e pautas sociais contemporâneas. Antes do relato, Clara já tinha um número considerável de seguidores em seu perfil justamente pelos textos que publicava. Em questionamentos decorrentes do relato, em que se levanta a hipótese do testemunho ter viés capitalizador de novos seguidores, Clara argumentou que já detinha certa reputação e capital social nas redes digitais.

${ }^{6}$ Texto originalmente para acesso em modo público, atualmente indisponível: <https://goo.gl/RFjx65>. Acesso em 12 fev 2018. Partes do relato original podem ser encontradas nas seguintes fontes: <http://twixar.me/DSjK>, <http://twixar.me/4SjK> e <http://twixar.me/5SjK>. Acesso em 17 abr 2019.

7 Entendemos que existem diferentes vertentes de movimentos feministas. 0 lema em questão é utilizado com frequência em manifestações diversas contemporâneas na América Latina. Não foram achadas as origens da expressão, que é, contudo, facilmente encontrada na web.
}

Dossiê A Música e suas Determinações Materiais - https://revistaecopos.eco.ufri.br/ 
considero um tapa na minha cara que a banda do felipe, a apanhador só, escreva e toque e grave uma música que se chama "linda, louca e livre", um dos gritos de guerra das feministas. não há nada de feminista ou de desconstruído nesse músico e, mesmo que não seja ele o autor da canção, acho uma piada de mal gosto imensa que o felipe fique no palco tocando ela durante os shows. acho histérico.

O que poderia ter sido uma disputa envolvendo a esfera íntima de agentes como Clara, Felipe e pessoas mais próximas ao ex-casal tomou, contudo, dimensões públicas a partir do espalhamento do texto de Clara, através de compartilhamentos e comentários no Facebook, e a significativa repercussão que ele adquiriu. A publicação conseguiu movimentar quase 8 mil compartilhamentos, 2,5 mil comentários e mais de 58 mil reações ${ }^{8}$. Também fez, à época, com que o nome da banda chegasse aos trending topics do Twitter, além de pautar os principais jornais diários do país - não apenas a imprensa especializada em música ou editoriais musicais. Ainda que o Apanhador Só não faça parte de um cenário mainstream da indústria musical brasileira, a banda possui certa projeção nacional, tendo obtido valores consideráveis para suas produções através de financiamento coletivo ${ }^{9}$, e, naquele momento, iniciava a turnê de divulgação do seu terceiro álbum. Na noite da publicação de Clara, o grupo tinha marcado o primeiro de seus dois shows, nos dias 16 e 17 de agosto, no Rio de Janeiro, com ingressos esgotados; na tarde seguinte, anunciou a paralisação de suas atividades.

Essa cadeia de eventos e contornos nos suscitou as questões sobre as quais nos debruçamos aqui: quais foram as estratégias e ações desenvolvidas pelo grupo para contornar esta crise midiática e como essas ações foram percebidas pelo público? Desta maneira, partindo da proposta de acontecimentos em rede (Henn, 2014), nossos objetivos residem em: 1) compreender as construções identitárias da banda que agenciam o relato de Clara e indiciam uma ruptura de coerência expressiva (Pereira de Sá; Polivanov, 2012) ou de performance (Polivanov; Carrera, 2019), desdobrando para suas afetações e proliferação de sentidos; e 2) identificar os modos através dos quais o Apanhador Só

\footnotetext{
8 Dados coletados em: 20 de março de 2019. Publicações seguintes, feitas entre 16 e 22 de agosto, em que Clara contextualizou o seu depoimento, ou mesmo em que expôs interações e reações que teve ou recebeu desde então, não chegaram nem a 10\% do engajamento (curtidas, compartilhamentos e comentários) da publicação original.

${ }^{9} \mathrm{~A}$ banda já conseguiu realizar dois projetos de crowdfunding pela plataforma Catarse, angariando um total de 163 mil reais (valor acima da meta original) para a gravação de dois de seus álbuns e a realização de uma turnê. Vide: <https://goo.gl/Aza5Sv>. Acesso em 22 fev 2019.
}

\section{Dossiê A Música e suas Determinações Materiais - https://revistaecopos.eco.ufri.br/}


buscou lidar com este confronto. Assim, além da denúncia de violência de gênero ${ }^{10}$ envolvendo um conjunto musical como potencial marcador de visibilidade, nosso argumento consiste, fundamentalmente, na percepção pelo público do Apanhador Só de uma ruptura na coerência expressiva da banda como agenciadora de tamanha repercussão.

Não pretendemos conceber, desse modo, como estáveis ou harmônicas as relações entre artistas e públicos - nem tampouco nos colocarmos numa posição de questionar se o testemunho de Clara seria verídico -, mas entendemos que a sua publicação foi catalisadora de diversos desdobramentos e eventos, em distintas camadas de temporalidades, não sendo possível demarcar pontos finais cronológicos no acontecimento.

Buscamos, contudo, delimitar aqui os momentos e movimentos do acontecimento: a) publicação de Clara Corleone; b) três manifestações da banda a este respeito em sua página no Facebook e; c) os comentários do público às postagens feitas pelo grupo. Iremos, neste artigo, nos debruçar sobre os dois últimos pontos, observando, portanto, o posicionamento da banda e de parte de seus seguidores. Em relação aos comentários do público, selecionamos para análise os três que obtiveram mais reações em cada uma destas publicações, totalizando, assim, um conjunto de nove textos. As postagens da banda, individualmente, são aqui percebidas como um microevento dentro do metaacontecimento. Para guiar nosso olhar na análise, nos inspiramos em processos metodológicos oriundos da Análise de Construção de Sentidos em Redes Digitais (Henn, 2014; Pilz, 2017) e da Análise de Conteúdo (Bardin, 1977).

\footnotetext{
${ }^{10}$ Entre os dias 16 e 22 de agosto, Clara atualizou seu perfil no Facebook dez vezes com conteúdo textual relacionado ao seu relato e desdobramentos. Nestes novos textos, comentou a repercussão entre a sociedade, sobretudo mulheres; ofereceu novas perspectivas sobre pontos entendidos como dúbios ou conflitantes (inclusive a partir das manifestações da banda); demonstrou que artistas locais lhe ofereceram apoio, mas questionou as manifestações serem privadas e não em modo público de seus perfis ou páginas. Estas atualizações, contudo, encontram-se atualmente indisponíveis, seja pela alteração de privacidade no Facebook (de público para outros modos restritos) ou por exclusão de Clara. Praticamente todas as suas publicações imediatamente seguintes ao relato fazem menção a ele e sua repercussão. Das que ainda podem ser acessadas, Clara descreve ou cita depoimentos de apoio, identificação, questionamento sobre machismo e relacionamentos, além de suas próprias afetações após o testemunho.
} 


\section{A construção identitária da banda e a quebra de expectativa com o testemunho}

O Apanhador Só é um grupo gaúcho cuja sonoridade tem inscrições no rock - mais especificamente, no indie rock, sendo rotulado por crítica e fãs como um som alternativo ou experimental, embora possa haver discordâncias quanto à pertinência dessas categorias, sobretudo a partir de uma ideia de fluidez dos gêneros musicais (Pereira de Sá; Janotti Júnior, 2018) e de estratégias mercadológicas (Frith, 1996; Janotti Júnior, 2003). Em atividade desde 2003, a banda possui três álbuns e outros três compactos lançados. É formada por Alexandre Kumpinski (vocalista e guitarrista), Fernão Agra (baixista) e Felipe Zancanaro (guitarrista e percussionista); nos shows, outros músicos completam a formação. Ganhou certa notoriedade nacional, sobretudo para um grupo oriundo do Rio Grande do Sul, embora esteja distante do simplista rótulo de rock gaúcho (Nunes; Silveira, 2015).

No início da carreira, o grupo esteve na plataforma da Trama Virtual ${ }^{11}$ para alcançar mais visibilidade. No festival Lollapalooza de 2014, em São Paulo, logo na primeira música de sua apresentação a banda utilizou o recurso do telão do palco para mostrar imagens de violência policial, figuras políticas e político-religiosas, protestos contra a Copa do Mundo no Brasil e as jornadas de junho de 2013, buscando afiliar-se a um ideal performático de engajamento político-ideológico crítico mais comumente atrelado à linha da esquerda política brasileira.

Através da observação e análise da obra, das estratégias de comunicação do grupo ao longo de sua carreira e a partir de reportagens, entrevistas e críticas, Giorgis (2017) aponta a proximidade entre o Apanhador Só e a cibercultura, nos usos que o grupo fez de potencialidades da cultura digital e de práticas coletivas, como conversações em rede (tanto para bate-papo com o público, quanto para processos de decisão de

\footnotetext{
11 Tratava-se de um serviço que tinha a proposta de armazenar e disponibilizar em um site, sem custos, parte do trabalho de artistas independentes que não tinham contrato com a gravadora Trama. Foi idealizado em 2002 e encerrou as atividades em 2013.
}

Dossiê A Música e suas Determinações Materiais - https://revistaecopos.eco.ufrj.br/

ISSN 2175-8689 - v. 23, n. 1, 2020

DOI: 10.29146/eco-pos.v23i1.27551 
direcionamentos do grupo) e disponibilização de materiais audiovisuais. O grupo promove também uma espécie de distanciamento (ora voluntário, ora involuntário) de grandes veículos de comunicação e produção musical em favor de emergentes veículos enraizados na ambiência digital. Nesse sentido, tanto o seu lançamento mais recente, Meio Que Tudo é Um (2017), quanto o anterior, Antes Que Tu Conte Outra (2013), foram viabilizados através de financiamento coletivo. Além disso, em apresentações ao vivo, a banda também tem o hábito de passar o chapéu pedindo dinheiro. Em seu site, é possível ouvir toda a sua discografia gratuitamente ${ }^{12}$.

Essa presença online e a ambiência relacional criada com seus fãs não só praticamente impossibilitou o silêncio do grupo, como também convocou seus admiradores a tomarem partido, a escolherem posicionar-se ao lado do grupo ou ao de Clara, gerando múltiplos embates discursivos, em processos de disputas e negociações autorreflexivas com seus gostos, filiações e processos identitários. Nesse sentido, apontamos que, além dos tensionamentos no relacionamento trazidos por Clara, intrinsicamente dignos de repúdio, há a intencionalidade em sua postagem-testemunho de uma ruptura na construção identitária da banda, uma quebra no ideal de coerência expressiva (Pereira de Sá; Polivanov, 2012) e na performance (Polivanov; Carrera, 2019) que a mesma vinha construindo e mantendo, ao revelar o que seria um comportamento anti-feminista, por assim dizer, de Zancanaro. Clara explicita este tipo de incômodo como força motriz de seu relato:

não pode, agora, a banda tocar uma música que pague de bacana sobre como o homem deixa a mulher livre para ser o que ela quiser dentro duma relação. pra cima de moi não vai rolar. quer ter uma relação bela e adulta com alguém? seja honesto, tenha respeito, tenha carinho. tudo isso faltou. faltou pra caramba.

Ao caracterizar "Linda, louca e livre" como uma música em que "o homem deixa a mulher livre para ser o que ela quiser dentro de uma relação", Clara não destaca trechos líricos da canção, apenas o título. Contudo, versos como "eu não te quero de branco, eu não te sonho no altar" ou "eu não quero que esse elo lindo se transforme em algema"

$12<$ http://www.apanhadorso.com/>. Acesso em 18 fev 2019.

Dossiê A Música e suas Determinações Materiais - https://revistaecopos.eco.ufrj.br/ 
corroboram sua perspectiva. É nesse sentido que a letra ${ }^{13}$ expõe o que pode ser caracterizado como liberdade em um relacionamento (entendida em sentido amplo, pois não há qualquer definição mais precisa do que seria esta liberdade); narrada em primeira pessoa, apresenta, ao que parece, uma união vigente, e uma promessa de independência de comportamentos e ausência de simbolismos de estabilidade e perenidade. A canção é a décima quarta e penúltima em Meio que tudo é um; é performada através de voz e violão, com ritmo lento e muito próximo do imaginário polissêmico da MPB.

O discurso de Clara rapidamente se propagou e ganhou endosso por parte do público, corroborando a percepção de uma ruptura na coerência expressiva da banda. Os tweets abaixo demonstram o reforço de posicionamento alinhado ao testemunho de Clara.

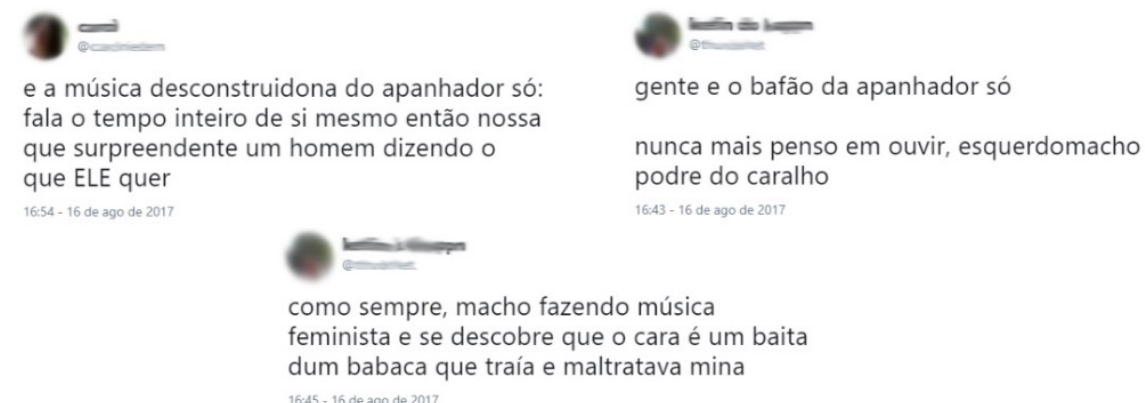

Figura 1 - Tweets que atribuem incoerência expressiva ao Apanhador Só

Fonte: Twitter, 2017

\section{Ruptura de coerência expressiva}

A noção de "coerência expressiva" aparece na obra A representação do eu na vida cotidiana, de Erving Goffman (2009)루 e é retomada por Pereira de Sá e Polivanov (2012) e Polivanov (2014), a partir também do pensamento de Anthony Giddens (2002), como categoria para se pensar as performances de si nos sites de redes sociais (SRSs). Em

\footnotetext{
13 "Eu não te quero de branco / Eu não te sonho no altar / Eu te quero linda, louca e livre / Lado a lado, enquanto menos faça algum sentido estar / Lado a lado, frente a frente / Dois elos de uma corrente / Que o acaso aos poucos / Vai fazendo e desfazendo encadear / E mesmo que haja medo / De te perder por aí de vista / Tanto quanto me é possível / Eu não quero que esse elo lindo / Se transforme em algema". Disponível em: <https://www.ouvirmusica.com.br/apanhador-so/linda-louca-e-livre/>. Acesso em 25 nov 2019.

${ }^{14}$ Obra publicada originalmente em 1956.
}

\section{Dossiê A Música e suas Determinações Materiais - https://revistaecopos.eco.ufrj.br/}


síntese, a ideia proposta é que, na contemporaneidade, a partir de uma maior liberdade nos processos de construção de identidade, somos convocados a criar nossas próprias narrativas autobiográficas e a fazê-lo de modo minimamente consistente ao longo de nossas vidas, buscando criar, assim, performances críveis e percebidas como autênticas sobre como desejamos ser vistos pelos outros, algo que ganha nova complexidade no âmbito dos SRSs, devido ao próprio agenciamento que tais agentes realizam em nossas redes. De qualquer maneira, no pensamento de Goffman, essas performances ${ }^{15}$ são cotidianas e têm a intenção de convencer $o$ outro sobre determinado aspecto de nossas personalidades.

Assim, as narrativas e ações tomadas pelo Apanhador Só são performances que fazem parte da identidade que a banda deseja construir ${ }^{16}$, algo que, por sua vez, só pode se dar numa relação social e semiótica com a figura da alteridade (neste caso, os seguidores da banda nos SRSs são seus maiores interlocutores). Dessa forma, há um jogo de negociação entre o que é esperado, o que se deve e o que não se deve performar na busca pela manutenção da coerência. Em outras palavras, há uma expectativa de alinhamento entre a performance sonora, lírica e discursiva de outra ordem do grupo e suas atitudes em esferas pessoais e/ou íntimas.

Contudo, Goffman também propôs que nessa manutenção da coerência expressiva estamos sempre suscetíveis a atos falhos - o que Polivanov e Carrera (2019) apontam como rupturas performáticas, destacando que

qualquer olhar sobre tais rupturas performáticas em sites de redes sociais deve entender seus agentes e efeitos enquanto redes necessariamente sociotécnicas, enquanto ações distribuídas entre diversos actantes que não devem ser vistos isoladamente. (Polivanov; Carrera, 2019, p. 17)

\footnotetext{
${ }^{15}$ Cabe destacar que os estudos sobre performance, bem como o próprio termo, possuem vertentes de significado e utilização distintas. Como apontam Amaral, Soares e Polivanov, "o termo performance vem sendo utilizado por diversas correntes da Antropologia, Linguística, Sociologia, estudos de gênero e estudos de Comunicação, entre outros" (2018, p. 65). Com base em Taylor (2013), os autores argumentam que os estudos sobre performance, a partir dos olhares francófonos e anglo-saxônicos, estão voltados para as dimensões da teatralidade e do espetáculo, em uma corrente, e da ação e da representação, em outra. Esta segunda vertente vai se deter sobre o que fazem os indivíduos e como se apresentam para os outros cotidianamente; é nela que Goffman se encontraria.

${ }^{16}$ Ainda que o autor estivesse lidando com a categoria de atores sociais individualmente em sua obra, assumimos aqui que boa parte de seus argumentos pode ser igualmente relevante para se pensar um grupo de sujeitos - neste caso, a banda.
}

Dossiê A Música e suas Determinações Materiais - https://revistaecopos.eco.ufrj.br/ 
Nesse sentido, a ruptura não se dá somente através de uma relação bilateral direta entre o ator/personagem e sua plateia, para usar as metáforas de Goffman. 0 que a ruptura do Apanhador Só nos dá a ver são justamente os atravessamentos nessa relação entre uma série de agentes (humanos e não-humanos), envolvendo: a postagemtestemunho de Clara e ela mesma; o próprio Facebook e outros SRSs, que permitiram que o discurso fosse rapidamente difundido; os sujeitos que o compartilharam e que teceram seus comentários a respeito do ocorrido; os integrantes da banda, dentre outros. Assim, uma narrativa de natureza a princípio íntima foi externalizada e visibilizada pela mediação das redes digitais, que passam a constituir parte significativa da performance da banda (sua narrativa e seus modos de lidar) e da forma como o público (entre fãs, nãofãs, haters e anti-fãs) vai interpretá-la.

Nesse processo de interpretação e (re)significação de performances, a ruptura de coerência expressiva pode levar a uma ideia de mentira, de hipocrisia. Ao acionarmos a teatralidade de Goffman, notamos que etimologicamente a palavra hipócrita, do grego hypókrisis, correspondia ao ato de desempenhar um papel teatral, não necessariamente com uma conotação negativa (Sibilia, 2015). Assim, alguns dos sujeitos envolvidos no acontecimento reverberaram o sentimento de que a banda estaria sendo hipócrita ao lançar uma canção com inspiração feminista enquanto um de seus membros teria tido comportamentos, no mínimo, machistas, gerando, conforme argumentamos, a ruptura em sua coerência expressiva. Contudo, é pertinente elucidar que a manifestação de Clara originou diversas outras respostas, inclusive com sentidos inversamente proporcionais, de repúdio e apoio à banda, de separação entre o sujeito artista e o sujeito ex-cônjuge de Clara, entre outros binarismos possíveis.

Nessa rede de mediações e interseções, na qual o acontecimento em tela constituise e reverbera, há que se considerar, do mesmo modo, a dimensão performativa da própria postagem de Clara. Na composição fluida daquilo que Charles Taylor (1989) chama de panóplia de máscaras virtuais, pode ocorrer, portanto, uma oscilação entre a condição de vítima (fundamental para o desencadeamento do acontecimento) e as possíveis minimizações desse pressuposto, e até mesmo o seu rechaço.

\section{Mobilizações em redes digitais: ativismo de fãs e acontecimento em rede}

Dossiê A Música e suas Determinações Materiais - https://revistaecopos.eco.ufrj.br/

ISSN $2175-8689$ - v. 23, n. 1, 2020

DOI: 10.29146/eco-pos.v23i1.27551 
Se o primeiro dos dois shows com ingressos esgotados no Rio de Janeiro (em 16 de agosto) aconteceu dentro do esperado, na noite seguinte, quando o testemunho de Clara já circulava e era replicado em redes digitais e portais de notícias, o concerto foi reconfigurado para uma performance solo de Alexandre, com apenas voz e violão. No evento virtual desses shows no Facebook, diversas pessoas publicaram a venda de ingressos, indicando o relato de Clara (ou o próprio Felipe) como motivo. Outros shows anunciados da turnê Meio que tudo é um foram cancelados pelos seus produtores - sob pedidos do público nos comentários em publicações de suas páginas ou perfis em sites de redes. Ou seja, além da rede de debates envolvendo pessoas com ou sem apreço, ou mesmo conhecimento, do Apanhador Só, percebemos mobilizações para ações práticas em desfavor do grupo, num sentido de boicote, lideradas pelos seus próprios fãs.

Ao refletir sobre as similaridades entre os movimentos sociais contemporâneos e a cultura de fãs, Brough e Shrestova (2012) entendem que há atravessamentos pertinentes entre ambos no que diz respeito a efeitos de mobilização e afetos envolvidos. Assim, ainda que reservem cuidados ao tomar todos os atos de engajamento como políticos, partilham da ideia de "ativismo de fãs" (Bennet, 2012; Amaral; Souza; Monteiro, 2015). Amaral, Souza e Monteiro (2015) apontam que essa forma de ativismo, intimamente mediada pelo entretenimento e a cultura pop, pode ser parte de uma demonstração de fidelização com o artista adorado, ou reafirmação de laços construídos em torno dele, ao ponto em que esses artistas são capazes de engajar politicamente sua base de fãs em prol de causas nas quais acreditam. Da mesma forma, os próprios fandoms ${ }^{17}$ idealizam mobilizações sem a convocação ou mesmo participação do objeto que inicialmente os une em laços afetivos.

Embora não seja nosso foco neste momento, o que a ruptura do Apanhador Só indicia é um certo tensionamento na ideia do ativismo de fãs, uma vez que, embora de uma forma geral a rede de debates se estenda para fora do público do grupo, neste caso há muitos fãs que se voltam contra a banda. Nesse sentido, se juntam aos discursos de condenação, propondo boicotes (como a revenda de ingressos e cancelamento de shows).

${ }^{17}$ Fan + kingdom (fã + reino). 0 termo designa o grupo de fãs de um determinado artista ou produto da cultura pop.

Dossiê A Música e suas Determinações Materiais - https://revistaecopos.eco.ufrj.br/

ISSN 2175-8689 - v. 23, n. 1, 2020

DOI: 10.29146/eco-pos.v23i1.27551 
Como demonstraremos em nossa análise empírica da recepção das manifestações do Apanhador Só, há discursos que apontam para uma ruptura nos laços afetivos, como causa e efeito, a partir da ruptura de expectativa,; fãs (ou até-então-fãs) que querem expressar a sua posição de não mais associados ao grupo. Ex-fãs que demonstram sua decepção e atitudes doravante como forma de dimensionar, individualmente, a potencialidade do relato e a intensidade com que se lida com seus desdobramentos.

Ainda que Valenzuela (2014, p. 42) defenda que "o uso de redes sociais parece ser uma ferramenta significativa para certas formas de ativismo", o autor demonstra ressalvas quanto à influência mediante outros tipos de protestos. Nesse sentido, as mobilizações, embora organizadas em rede, influenciam direta e rapidamente em um show reconfigurado do grupo e no cancelamento da turnê (o que, via de regra, acarreta prejuízos para os agentes envolvidos nela, como produtores locais, casas de shows etc.). É sob essa perspectiva que Henn (2014) formula a categoria nomeada ações e protestos virtuais, uma das seis tipificações de ciberacontecimentos ou acontecimentos em rede.

Por ciberacontecimentos entende-se aqueles que se processam a partir de articulações em SRSs. Trata-se de acontecimentos que, na condição de expressões contemporâneas da cibercultura, constituem-se em redes digitais e geram narrativas de natureza convergente e transmidiática: sua potência vincula-se ao nível de afetação que propulsiona, intensificada pela experiência desse acontecer em rede (Henn, 2014). Seu poder de constituição e propagação vincula-se à ação dos atores sociais, ainda que se possa pensar em outros agentes sociotécnicos atuando nesses processos.

Na perspectiva de Quéré (2005), o acontecimento, além de provocar, em algum nível, uma ruptura, também inaugura um processo de construção de sentidos. E mais, ele necessariamente precisa articular-se no nível da experiência, mesmo que simbólica: o acontecimento só se constitui como tal na medida em que afeta sujeitos ou processos. Nas dinâmicas das redes digitais, há uma potencialização desse acontecer, nos mais variados campos e com desdobramentos diversos: dimensões privadas e públicas transmutam-se. Alguém se sente diretamente afetado por uma canção, a partir da experiência privada com um dos seus autores. Manifesta-se no Facebook e isso reverbera, gerando pautas 
jornalísticas ${ }^{18}$, mobilização de fãs e toda uma rede discursiva, que culmina com a interrupção de uma turnê da banda em foco. Todas as tintas do ciberacontecimento estão aqui delineadas.

Os ciberacontecimentos possuem, pelo menos, três dimensões a se considerar: os processos transnarrativos e hipermidiáticos que incluem a presença de outros atores fora dos núcleos do jornalismo tradicional; a reverberação instantânea, que passa a ser incorporada na própria narrativa, também a constituindo; e a eclosão desses outros modos de acontecimentos que se tramam no cenário de conexões sistêmicas altamente complexas (Henn, 2014). Não são apenas formas distintas de constituição que esse tipo de acontecimento opera; ele também se inscreve em novas arquiteturas narrativas, potencializadas pelas redes digitais - disputas de sentidos e de territórios simbólicos são desencadeadas nesses processos.

Ao propor categorizações para diversas naturezas destes acontecimentos, Henn (2014) propõe seis tipificações (considerando também atravessamentos entre as mesmas): 1) mobilizações globais, 2) exercícios de cidadania, 3) afirmações culturais, 4) entretenimentos, 5) subjetividades e 6) ações e protestos virtuais. A última delimitação - na qual situamos o relato de Clara, seus desdobramentos e a crise em que o Apanhador Só é envolvido - Henn (2015, p. 214) define como as mobilizações que concentram nas redes "sua força contestadora" e suas potencialidades, além do foco em pautas pontuais. Nesse sentido, são ações e protestos virtuais as narrativas centradas e espalhadas através, por exemplo, das hashtags \#MeuPrimeiroAssédio ${ }^{19}$ e \#MeuAmigoSecreto ${ }^{20}$.

\footnotetext{
${ }^{18}$ Como, por exemplo, as matérias que foram publicadas n'O Globo: $<$ http://twixar.me/pCjK > e na Folha de São Paulo: <http://twixar.me/BCjK>. Ambas matérias relatam o evento, partindo do relato de Clara Corleone. Acesso 17 abr 2019.

${ }^{19} \mathrm{~A}$ hashtag, elaborada pelo projeto Think Olga em 2015 a partir de publicações em rede que sexualizavam a participante Valentina, de 12 anos, em um reality show, foi criada para que mulheres relatassem suas experiências com assédio sexual, demonstrando que o caso da menina não era isolado.

${ }^{20} \mathrm{~A}$ hashtag \#meuamigosecreto foi inaugurada em novembro de 2015, próximo ao Dia Mundial de Combate à Violência contra a Mulher (25/11). Seu propósito era (a partir das dinâmicas da tradicional brincadeira de final de ano do amigo secreto, ou amigo oculto, em que os participantes dão dicas sobre o seu amigo sorteado para que os outros participantes descubram quem este é) fomentar e agregar narrativas de mulheres relacionadas a atitudes que as fazem se sentir oprimidas e denúncias de atitudes machistas ou sexistas, sem revelar quem as praticou. As formas de uso e espalhamento da hashtag, contudo, foram se modificando, de um caráter de denúncia espirituosa, para indiretas, uso de humor, ou mesmo tentativas de subverter a mobilização, como a hashtag \#minhaamigasecreta (PILZ, 2016).
}

Dossiê A Música e suas Determinações Materiais - https://revistaecopos.eco.ufrj.br/ 
Nas investigações sobre processos constitutivos de acontecimentos em redes digitais $^{21}$, problemáticas que envolvem diversidade de gêneros e performances de si ganharam relevância. Além das hashtags citadas acima, uma série de eventos vinculados a estas temáticas engendraram formas no ambiente dos SRSs, sinalizando para sua força propulsora. Ao mesmo tempo, esse ambiente revelou-se espaço de natureza conflitiva, com disputas de territórios, apropriações de distintas especificidades, lógicas algorítmicas e vulnerabilidades sistêmicas (Oliveira; Osório; Henn, 2019; Henn; Kolinsk Machado; Gonzatti, 2019; Henn; Pilz; Machado, 2018; Malessa; Esmitiz, 2018).

\section{Afetações em rede e gerenciamento da crise}

De forma a nos atentarmos mais especificamente para as questões que nos movem neste ciberacontecimento, delimitamos como corpus de pesquisa empírica as estratégias e desdobramentos do Apanhador Só no contorno desta crise, a partir de: a) três publicações em sua página no Facebook, local de gênese do acontecimento e principal dispositivo de relacionamento do grupo, entre os dias 17 e 30 de agosto de 2017, e b) três principais comentários em cada uma delas ${ }^{22}$. Assim, inspirados na análise de conteúdo (Bardin, 1977), a partir dos doze textos selecionados (três publicações do grupo e três principais comentários em cada uma delas), elaboramos reflexões acerca dos argumentos e posicionamentos mobilizados, suas subjetividades e representatividades, como parte fundamental da repercussão do acontecimento.

É importante destacar que o caso aqui analisado sob o nosso olhar interpretativo não se dá de modo isolado na cultura digital. Observamos um cenário marcado pelo ativismo de fãs potencializado pela cultura digital e por uma cobrança crescente para que pessoas públicas, como músicos e celebridades, sigam posicionamentos coerentes e aceitáveis frente a suas audiências, sob pena de serem "cancelados" caso denúncias de

\footnotetext{
${ }^{21}$ Pesquisas desenvolvidas no LIC-Laboratório de Investigação do Ciberacontecimento, cadastrado no CNPq e lotado no PPGGCOM da Universidade do Vale do Rio dos Sinos, Unisinos.

${ }^{22}$ No que compete à observação no Facebook, o site oferece três possibilidades de visualização: (a) Comentários mais relevantes, (b) Mais recentes e (c) Comentários mais relevantes (sem filtros). Optamos pela última, uma vez que a isenção de filtros permite que tenhamos acesso aos comentários que, na prática, obtiveram mais reações e, teoricamente, não expõe com maior visibilidade os comentários publicados por conexões próximas, tendo em vista os perfis utilizados para estas observações.
}

Dossiê A Música e suas Determinações Materiais - https://revistaecopos.eco.ufrj.br/

ISSN $2175-8689$ - v. 23, n. 1, 2020

DOI: 10.29146/eco-pos.v23i1.27551 
comportamentos contrários sejam expostos ${ }^{23}$. Nesse sentido, o caso do Apanhador Só também inaugurou uma publicação no Medium ${ }^{24}$ chamada Bandas que você não deveria escutar (posteriormente excluída da plataforma), listando artistas que já foram denunciados em contextos similares ${ }^{25}$.

\section{Primeira manifestação da banda: hiato e posicionamento somente após reflexão}

O Apanhador Só se manifestou pela primeira vez mais de vinte e quatro horas após o testemunho de Clara (figura 2). Reiteramos que em pesquisa exploratória sobre os desdobramentos do relato, percebemos diversas publicações no sentido de cobrança de um posicionamento do grupo. Este primeiro texto do Apanhador Só relata afetações e pesares com a situação (não indicando se em relação à sua carreira ou ao ocorrido com Clara anos antes). Nesta publicação, o grupo anunciou a suspensão temporária das suas atividades, além da possibilidade do caso promover mais discussões sobre machismo, referindo-se aos seus integrantes como "dispostos a rever e modificar cada vez mais em cada um de nós". Na nota, a banda também prometeu pronunciar-se "sobre o assunto" quando "for possível".

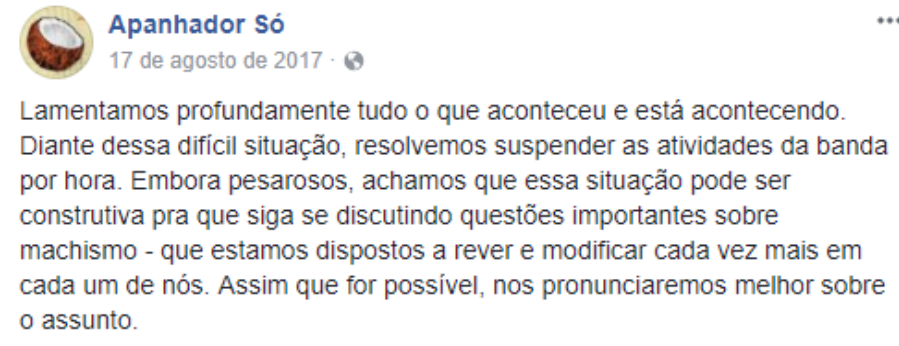

${ }^{23} 0$ termo "cancelamento" tem sido usado recentemente por fãs em cenas musicais diversas para se referir ao movimento de deixar de consumir músicas (e demais produtos) de determinados artistas, visibilizando tal comportamento em plataformas de redes sociais através de hashtag homônima ou similar (como \#cancelado). Podemos nos referir aqui a um outro caso de denúncia de violência contra mulheres, que envolveu um membro do duo punk estadunidense PWR BTTM, analisado por Medeiros e Polivanov (2019). ${ }^{24}$ Plataforma de publicação de textos, similar ao formato blog, inaugurada em 2012. Os usos e apropriações do Medium dão-se de diversas formas, profissionais e não-profissionais, pagas e gratuitas; destaca-se o seu uso como meio de publicação de composições de cunho jornalístico (ainda que não necessariamente realizadas por jornalistas) e crônicas.

${ }^{25} \mathrm{O}$ compilamemento foi organizado por uma estudante de jornalismo do Rio Grande do Sul, inicialmente a partir de registros precedentes, como notícias de jornais e tweets, e posteriormente a partir de novos relatos fomentados pela criação da lista. Entre os artistas presentes nesta lista estão Criolo, CPM 22, Francisco El Hombre e Carne Doce. Em seguida, uma hashtag no Twitter, \#meuartistasecreto, em ressignificação da hashtag \#MeuAmigoSecreto, também passou a agregar este tipo de narrativa.

Dossiê A Música e suas Determinações Materiais - https://revistaecopos.eco.ufrj.br/

ISSN $2175-8689$ - v. 23, n. 1, 2020

DOI: 10.29146/eco-pos.v23i1.27551 
Figura 2 - Primeira manifestação da banda em sua página no Facebook Fonte: < http://twixar.me/QzsK> Acesso em 14 mar 2019

Dentro de nossa proposta metodológica, dos três comentários com mais reações, o primeiro tem aproximadamente ${ }^{26} 4000$ reações, o segundo 1500 e o terceiro $1200^{27}$ (figura 3); todos realizados por perfis com marcas identitárias femininas. 0 primeiro comentário destaca um trecho da nota da publicação original, inferindo que a decisão de suspensão das atividades dava-se, em verdade, não para rever atitudes, mas para evitar linchamento e shows vazios. O comentário classifica os integrantes como "cara de pau" e que teria sido suficiente encerrar a nota informando a suspensão das atividades (que, no texto do grupo, aparece no início e antes do trecho citado pelo comentários). 0 comentário também pede que, quando do retorno das atividades, o grupo pare de "fazer música desconstruidona \& de esquerda", alegando que "a luta de mulheres não é fonte de renda para homem misógino".

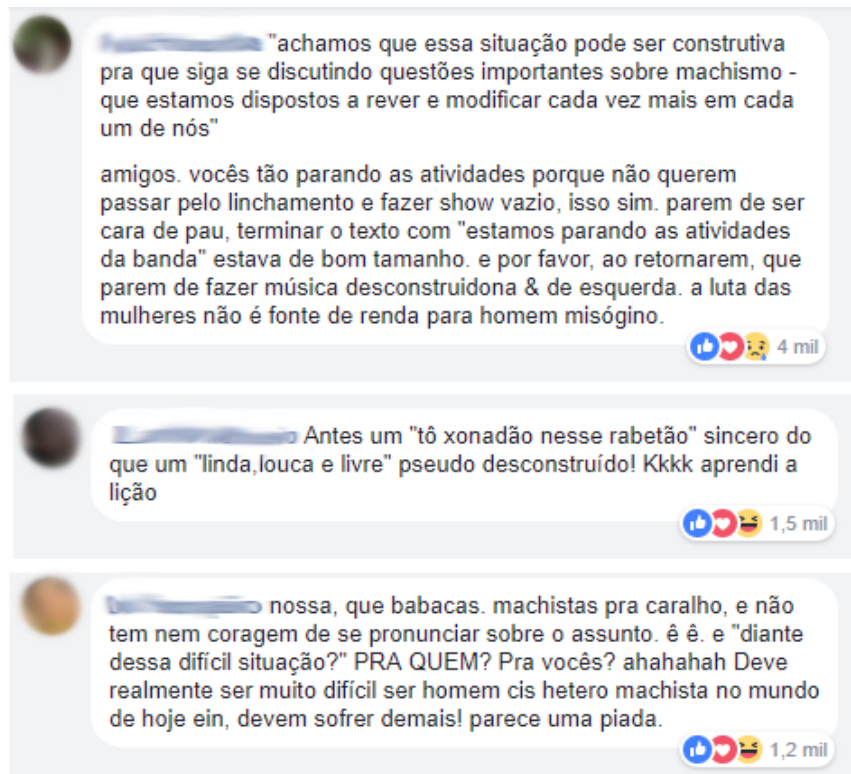

260 Facebook não informa o valor exato a partir de mil reações.

270 primeiro comentário teve 3,5 mil reações de "Curtir"; 508 de "Amei"; 10 de "Triste"; 3 de "Haha" (risada); 1 de "Uau" (surpresa) e 1 de "Grr" (raiva). 0 segundo comentário recebeu 1,2 mil "Curtir"; 143 "Amei"; 122 "Haha"; 1 "Triste" e 1 "Grr". 0 terceiro comentário recebeu 1,1 mil "Curtir"; 74 "Amei"; 24 "Haha"; 8 "Grr"; 5 "Triste"; 3 e "Uau".

Dossiê A Música e suas Determinações Materiais - https://revistaecopos.eco.ufrj.br/ 
Figura 3 - Os três comentários com mais reações à postagem no Facebook Fonte: mostra elaborada pelos autores

Embora uma das chaves de interpretação do primeiro comentário seja a ironia, no segundo, o uso deste recurso é mais explícito, com a utilização de kkk (símbolo para risadas em conversações textuais mediadas por computador) e trecho de uma letra de música de MC Lan ${ }^{28}$, artista de funk de São Paulo, aferindo preferência pela sinceridade deste cantor (o trecho da letra, tô xonadão nesse rabetão indica apego emocional às nádegas de uma mulher) do que a, em suas palavras, "pseudo desconstruída canção linda, louca e livre". O terceiro comentário com mais reações classifica os integrantes do Apanhador Só como "babacas e machistas", e sem "coragem de se pronunciar sobre o assunto". O perfil também aponta dúvidas sobre o trecho da nota que cita "uma difícil situação", questionando para quem especificamente seria difícil a situação. 0 recurso da ironia também é acionado, através de ahahahah (outra grafia de risada nas conversações em rede) e na afirmação de que "deve realmente ser muito difícil ser homem cis hetero machista no mundo de hoje ein, devem sofrer demais!”. O comentário também classifica a nota da banda como semelhante a uma piada.

\section{Segunda manifestação da banda: autocríticas e roda de conversa com o público}

A segunda manifestação da banda foi publicada em 25 de agosto, oito dias depois do primeiro posicionamento. Nesta nota, consideravelmente mais extensa do que a primeira $^{29}$, e que o Apanhador Só afirma ser fruto de "muito ouvir, refletir e conversar", o grupo alegou má interpretação de alguns pontos levantados por Clara, fazendo referência inclusive a publicações seguintes da própria onde a mesma esclarece interpretações errôneas de sua fala por parte do público; tece explicações sobre a composição da canção; coloca-se numa perspectiva de construção social masculina e de uma banda formada exclusivamente por homens, para repensar seu lugar e atitudes; propõe uma

\footnotetext{
$28<$ http://twixar.me/PzsK>. Acesso em 26 fev 2019.

${ }^{29}$ Esta é a única manifestação da banda em nosso escopo que não ilustraremos integralmente aqui devido à sua extensão. Disponível em: <https://www.facebook.com/apanhadorso/posts/1458331534249182/>. Acesso em 20 fev 2018.
}

Dossiê A Música e suas Determinações Materiais - https://revistaecopos.eco.ufrj.br/

ISSN 2175-8689 - v. 23, n. 1, 2020

DOI: 10.29146/eco-pos.v23i1.27551 
roda de conversa, na Casa de Teatro, em Porto Alegre, no domingo seguinte (27 de agosto) “com quem estiver disposto a fazê-lo de forma respeitosa - sobre os papéis que desempenhamos e o que podemos fazer para construir relações mais horizontais e saudáveis". O convite também aponta a preferência pelo espaço físico em detrimento das redes digitais, com a justificativa de que nele "a existência do outro é muito mais inteira, completa, humana".

A banda não defende Felipe, preferindo focar na problemática da canção "Linda, louca e livre" - premissa para o manifesto de Corleone, como já apontamos —, alegando que não havia qualquer intencionalidade de referencial feminista; mais precisamente, que o grupo desconhecia o lema feminista:

Sobre a canção "Linda, louca e livre", nunca foi nossa intenção que ela fosse uma música feminista. Por mais que o título possa apontar pra isso, se analisarmos a letra da música, percebemos que ela tem seu mote na vontade/busca por uma relação sincera e livre entre duas pessoas. Por desconhecimento, não sabíamos que as palavras "libre, linda y loca" eram um lema feminista latinoamericano. Se soubéssemos, teríamos problematizado internamente sobre o uso dessas palavras na canção.

Dessa forma, entendemos que o Apanhador Só tentou realizar um auto indulto com relação às acusações de que estaria tentando assumir algum tipo de protagonismo do movimento feminista com a música. Além disso, na proposta da roda de conversa o objetivo declarado foi o de "entender a opinião do público", sobre como as pessoas se sentiram ao ler o relato de Corleone, bem como "abrir um espaço" para que os integrantes da banda pudessem falar sobre a sua própria perspectiva. Houve, portanto, por parte do trio, a tentativa de expressar-se oferecendo e contrapondo discursos e rótulos sobre o grupo e seus integrantes, reconhecimento do próprio local de fala, e a criação de um espaço menos hierárquico para o debate sobre o acontecimento.

Novamente, todos os principais comentários (figura 4) foram realizados por perfis com marcas identitárias femininas ${ }^{30}$. Atentamos também para a relativa diminuição de

\footnotetext{
${ }^{30} 0$ primeiro comentário tem 506 Curtir (um sinal de concordância quase indiscutível em performances discursivas como essa); 34 Amei (um sinal de concordância mais enfática); 9 Triste; 2 Grr (tanto Triste quanto Grr podem mostrar concordância ou não com o que está escrito, já que podem enfatizar o tom de raiva ou decepção demonstrado no próprio comentário). As reações são representações diretas de como as pessoas se sentiram ao ler a publicação do Apanhador Só, em conjuntura com o comentário em questão. A
}

Dossiê A Música e suas Determinações Materiais - https://revistaecopos.eco.ufrj.br/ 
reações em cada um desses comentários, em comparação com os da figura 3 .

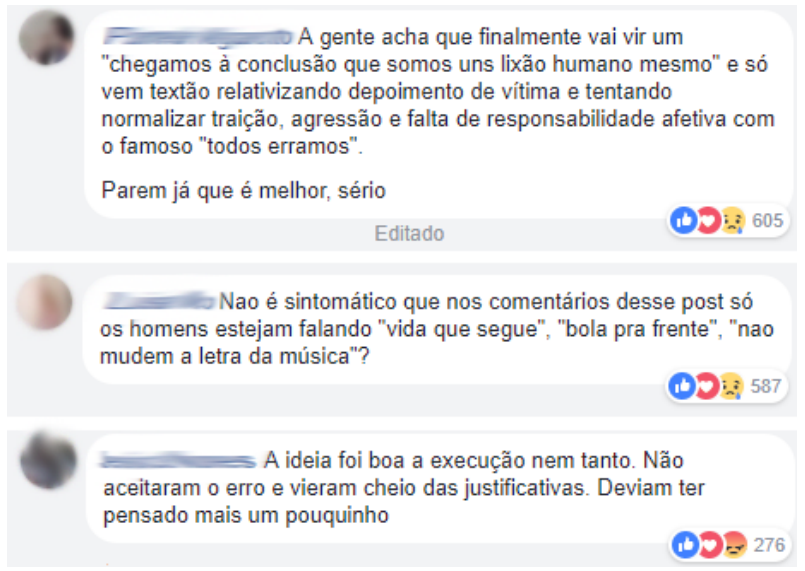

Figura 4 - Três comentários com mais reações à segunda postagem da banda Fonte: Facebook, 2017

O primeiro comentário em destaque aponta para uma quebra de expectativa, representativa de uma afetividade expressada; ao invés de ler um relato sobre como a banda estava errada, afirma que não passa de uma relativização do relato da vítima, além de ser uma tentativa de "normalizar traição, agressão e falta de responsabilidade afetiva". O segundo comentário realiza uma diferenciação de gênero nas conversações da publicação, apontando para como perfis com traços identitários masculinos estavam colocando panos quentes ou demonstrando apoio ao grupo, seguindo uma lógica de brotherhood of man ${ }^{31}$. Não desmerece nem deslegitima o que a banda escreveu; não é um comentário de apoio nem de crítica ao Apanhador Só per se, mas de uma diferenciação de afetos e manifestações de possíveis fãs homens da banda. Nesse sentido, há uma crítica

concordância é relativamente alta, dando a entender que pelo menos 506 pessoas também tiveram suas expectativas quebradas com a forma como a banda se portou nesse momento. 0 segundo comentário teve 557 Curtir, 23 Amei, 4 Triste, 2 Grr e 1 Haha. Nesse comentário o número de concordância também é significantemente alto, indicando que a maioria das pessoas nesta conversação concorda com a prerrogativa de que há uma união entre os homens quando o assunto em pauta é protagonismo feminista. 0 terceiro comentário tem menos reações, se comparado com os dois principais, tendo 265 Curtir, 9 Amei e 2 Grr, onde uma possível chave de leitura é a inconformidade nos modos como se sucedeu a roda de conversa.

310 termo tem origem na percepção de que homens do proletariado britânico no século XVIII defendiam seus próprios interesses, quaisquer fossem eles, através dos sindicatos, mas excluíam efetivamente as mulheres inseridas no mesmo contexto (Lake, 1992).

\section{Dossiê A Música e suas Determinações Materiais - https://revistaecopos.eco.ufri.br/}


com - ousamos afirmar - tendências feministas, que aponta a falta de problematização e o apoio que os fãs masculinos estenderam à banda, com expressões como "não mudem a letra da música". 0 terceiro e último comentário, por fim, de certa maneira elogia a proposta do gerenciamento (sem explicitar se o hiato, a roda de conversa ou outra situação), mas aponta que a prática ficou aquém do esperado. 0 argumento é baseado na falta de mea culpa, de deixar explícita a aceitação das inferências sobre seus comportamentos e no excesso de justificativas.

\section{Terceira manifestação da banda: agradecimento e promessa}

A terceira manifestação do Apanhador Só se deu após a convocação da roda de conversa, e tratou-se de um agradecimento da banda para as pessoas que participaram desse encontro (figura 5). Apesar de relatar a experiência do evento como "muito rica, de muito aprendizado, muita troca", a publicação não traz detalhes sobre a conversa com o público. Há também, por parte do Apanhador Só, uma promessa de repetição da roda de conversa em outras cidades onde a banda faria shows. No entanto, com base em publicações seguintes do grupo no Facebook, ou mesmo em busca por rastros digitais ${ }^{32}$, não encontramos indícios da realização desses eventos.

\footnotetext{
Apanhador Só

30 de agosto de 2017 .

Obrigado a todas as pessoas que compareceram no último domingo à roda de conversa na Casa de Teatro. Foi uma experiência muito rica, de muito aprendizado, muita troca e muito respeito entre todos os presentes. Sabemos que não é possível esgotar assuntos tão complexos em apenas uma ocasião, mas torcemos para que espaços de diálogo como esse se façam cada vez mais presentes ao nosso redor. Pra quem não é de Porto Alegre e não teve a oportunidade de participar, pretendemos repetir a

experiência nas cidades por onde passarmos quando retomarmos a agenda de shows.
}

Figura 5 - Terceira manifestação da banda em sua página no Facebook Fonte: < http://twixar.me/czsK>. Acesso em 24 fev 2019.

0 comentário com o maior número de reações apresentou 202, enquanto os seguintes, 109 e 108, respectivamente (figura 6). É importante mencionar que o

32 No Facebook e no Twitter, através de palavras-chave como "apanhador só", "roda de conversa" e "debate". Os únicos resultados encontrados faziam referência à roda de conversa em Porto Alegre.

Dossiê A Música e suas Determinações Materiais - https://revistaecopos.eco.ufrj.br/

ISSN 2175-8689 - v. 23, n. 1, 2020

DOI: 10.29146/eco-pos.v23i1.27551 
comentário com o maior número de interações tem um sentido de apoio à banda. Nele, o perfil questiona aqueles/as que estão criticando as ações do grupo ("qual é a solução pra vocês?") e afirma que o tipo de debate proposto pelo Apanhador Só é uma iniciativa que funciona, porque "ninguém toma conhecimento de luta sem debate e diálogo"33.

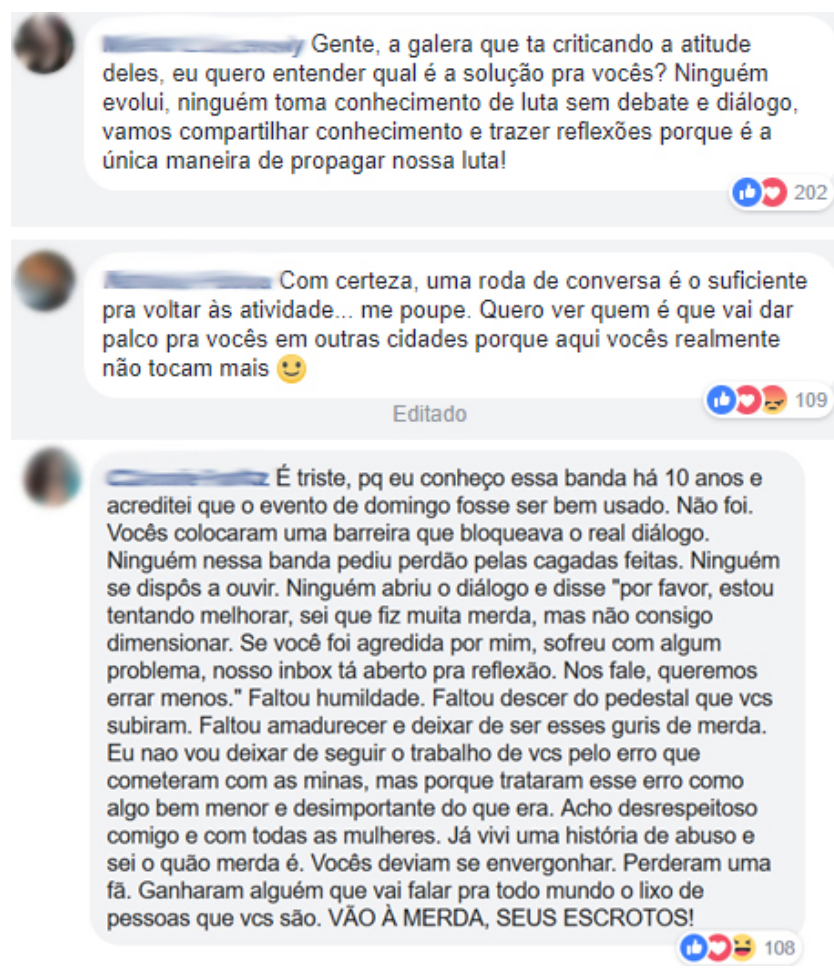

FIGURA 6 - Três comentários com mais reações à terceira postagem Fonte: <http://twixar.me/czsK>. Acesso em 24 fev 2019.

No segundo comentário, novamente a ironia é utilizada como forma de deslegitimar a ação da banda; ao questionar "quero ver quem vai dar palco pra vocês em outras cidades porque aqui vocês realmente não tocam mais", há um certo descrédito, um desafio, sobre

\footnotetext{
${ }^{33}$ A perspectiva desse comentário remete a um tipo mais liberal de feminismo, já que a pessoa sugere que homens também devem participar do ativismo para que haja uma mudança no sistema patriarcal. 0 feminismo liberal é uma linha insurgente do movimento dos anos 1960, quando debates sobre o materialismo histórico, liberalismo, marxismo e socialismo começaram a fazer parte do contexto feminista mais acadêmico (Okin, 2008). A linha separa espaço público e espaço doméstico como lugares que carecem de tipos diferentes de luta; nesse sentido, há um engajamento muito maior por parte das feministas liberais em relação ao espaço de trabalho do que em relação à violência doméstica, por exemplo. Diferentemente do feminismo radical, o feminismo liberal não parece se incomodar com certo protagonismo masculino, por isso essa linha é conhecida como sendo mais leniente a justificativas masculinas de se eximir de culpa.
}

Dossiê A Música e suas Determinações Materiais - https://revistaecopos.eco.ufrj.br/ 
a possibilidade de um retorno das performances ao vivo. Em relação ao comentário anterior, este engajou uma variação maior de reações ${ }^{34}$ apontando discordância com a visão de quem o fez. No terceiro e último comentário publicado, percebemos de forma mais nítida a narrativa da decepção de uma até-então-fã, ou ex-fã ("perderam uma fã e ganharam alguém que falar pra todo mundo o lixo de pessoa que vcs são"). Contudo, o comentário também indica que não vai "deixar de seguir o trabalho de vcs pelo erro que cometeram com as minas". Sublinhamos aqui a sinalização de um fracasso ou ineficiência no gerenciamento da crise, uma vez que, além da conotação da falta de coerência expressiva da banda e das atitudes de violência, a pessoa dá a ver que esteve presente na roda de conversa e houve certa frustração em relação ao que foi prometido, e, diante das circunstâncias dos acontecimentos, não houve interesse genuíno em assumir erros, projetar soluções ou mesmo abrir-se ao diálogo de forma não-unilateral.

\section{Considerações finais}

No sentido de que o testemunho de Clara, sobretudo a partir das potencialidades das plataformas de redes sociais, não é apenas pessoal, mas também político (conforme proposta de Carol Hanisch ${ }^{35}$ ), os múltiplos afetos envolvidos, atravessados por questões além de associações prévias com o Apanhador Só, e expressados nesta ambiência, geraram uma crise no grupo, que precisou ser gerenciada. Destacamos que houve uma percepção de ruptura na coerência expressiva da banda, através da canção "Linda, louca e livre" e do comportamento de Felipe Zancanaro no relacionamento amoroso, pontos presentes no relato de Clara. A partir do momento em que o público se identifica com, neste caso, uma banda, ele espera que suas expectativas sejam atendidas, que as respostas da banda estejam atreladas com o seu pensamento e posicionamento. 0 relato de

\footnotetext{
${ }^{34}$ Nessa segunda publicação observamos haver 81 Curtir, 20 Amei, 6 Grr e 2 Triste, o que mostra um número interessante (ainda que minoritário) de pessoas que não concordaram com a prerrogativa da hater. Da mesma forma, a terceira postagem não encontrou apenas concordâncias: observamos 87 Curtir, 18 Amei, 3 Haha (um tipo de reação que pode ser vista como irônica, dependendo da mensagem escrita) e $1 \mathrm{Grr}$ mostrando que, diferentemente do primeiro comentário, e assim como o segundo, não há uma concordância unânime das pessoas lendo ao comentário.

35 A feminista teria sido criadora da expressão "o pessoal é político". Vide: <https://goo.gl/YQTRuS>. Acesso 15 fev 2018.
}

Dossiê A Música e suas Determinações Materiais - https://revistaecopos.eco.ufrj.br/

ISSN $2175-8689$ - v. 23, n. 1, 2020

DOI: 10.29146/eco-pos.v23i1.27551 
Corleone é uma espécie de quebra nessa expectativa, um acontecimento que origina novos afetos em relação ao grupo, criando uma categoria a ser explorada em pesquisas futuras: a de ex-fãs. Isso se dá a partir do momento em que alguns fãs tomam conhecimento do relato-testemunho de Clara e passam a ter uma nova informação a respeito de um dos integrantes da banda (ainda que essa possa ser contestada ${ }^{36}$ ), informação que se chocaria fortemente com as performances do grupo até então. Há, assim, um desencaixe que desloca o fã para o lugar de ex-fã, e que, além disso, embaralha (ainda mais) as dimensões do público e do privado, da performance enquanto banda / artista e a performance enquanto sujeito no mundo.

Nas três manifestações do gerenciamento, como desdobramentos do acontecimento em rede, apontamos para 1) um primeiro momento de assimilação, resposta imediata (o hiato) e promessa de manifestação mais substancial; 2) a intencionalidade de tomada do protagonismo do discurso, como oferecimento de um ponto de vista próprio sobre o caso, extenso, pontual em determinados detalhes, na tentativa de colocar Clara e os desdobramentos em perspectiva, ou em relativização; 3) e a proposta de uma roda de conversa que encerra a lida com o caso num sentido de que o grupo fez o que poderia fazer após tudo o que veio à tona. Desta maneira, o hiato, que não tinha periodicidade demarcada, encerra-se em novembro de 2018, quando o Apanhador Só retomou as atividades de performances ao vivo. Desde então, contudo, a banda diminuiu drasticamente suas atualizações em SRSs, sem nunca mais mencionar a crise enfrentada em agosto de 2017. No perfil pessoal de Felipe Zancanaro, é possível ver algumas pessoas comentando piadas sobre o ocorrido ou deliberadamente xingando o músico e declarando apoio a Corleone, que, além de apagar diversas manifestações relacionadas posteriores ao testemunho inicial, também não mencionou mais a banda ou a repercussão do seu relato.

Por fim, vale destacar novamente que o acontecimento aqui debatido não é um caso isolado. Têm emergido nas redes com certa frequência denúncias vinculadas a outras bandas/artistas com contornos de rupturas performáticas e indícios do que tratamos por

\footnotetext{
36 Ressaltamos que não nos cabe nesse trabalho desempenhar o papel de julgamento de valores ou de determinar a veracidade do testemunho de Clara. Interessamo-nos pelas estratégias utilizadas pela banda para tentar manter o seu público e em como esse mesmo público respondeu às mesmas.
} 
ex-fãs, como o caso da banda queer estadunidense PWR BTTM (Medeiros; Polivanov, 2019). Para além de tais casos, há outros ainda que adentram a esfera política explicitamente, como o que envolveu o músico Roger Waters e seu posicionamento contrário ao então candidato à presidência no Brasil que acabou vencendo as eleições, caso analisado por Janotti et al (2018). Fica posta, assim, a emergência de uma categoria de posicionamento dos sujeitos até então pouco estudada no campo da comunicação e estudos de fandoms e música, a do/a ex-fã, e a visibilidade das disputas e negociações vinculadas às cobranças por performances coerentes dos artistas, tema sobre o qual seguiremos atentos.

\section{Referências bibliográficas}

AMARAL, Adriana; SOARES; Thiago \& POLIVANOV, Beatriz. Disputas sobre performance nos estudos de Comunicação: desafios teóricos, derivas metodológicas. Revista Intercom - RBCC (São Paulo, Online), vol. 41, n. 1, p. 63-79, jan-abr 2018.

AMARAL, Adriana; SOUZA, Rosana \& MONTEIRO, Camila. "De westeros no \#vemprarua à shippagem do beijo gay na TV brasileira". Ativismo de fãs: conceitos, resistências e práticas na cultura digital. Galaxia (São Paulo, Online), n. 29, p. 141-154, jun. 2015. Disponível em: <https://tinyurl.com/yyf2rc8g>. Acesso em 10 mar 2019.

BARDIN, Laurence. Análise de conteúdo. Lisboa: Edições 70, 1977.

BENNET, Lucy. Fan activism for social mobilization: A critical review of the literature. Transformative Works and Cultures, v. 10, 2012. Disponível em: <https://tinyurl.com/yxcmrx5f>. Acesso em 04 mar 2019.

BROUGH, Melissa \& SHRESTOVA, Sangita. Fandom meets activism: Rethinking civic and political participation. Transformative Works and Cultures. vol 10, 2012. Disponível em <https://tinyurl.com/y62ghdfc> Acesso em 13 mar 2019.

FRITH, Simon. Performing Rites: on the value of popular music. Harvard Univ Press:Cambridge, Massachussets, 1996.

GIORGIS, Belisa. Arqueologia da mídia da Apanhador Só: Produção de presença na Cibercultura Dissertação de Mestrado - Programa de Pós-Graduação em Processos e Manifestações Culturais, Feevale, 2017.

GIDDENS, Anthony. Modernidade e identidade. Rio de Janeiro: Jorge Zahar Editor, 2002.

GOFFMAN, Erving. A representação do eu na vida cotidiana. Petrópolis: Vozes, 2009.

HENN, Ronaldo. El ciberacontecimiento: producción y semiosis. Barcelona: Editorial UOC, 2014. 
Seis categorias para o ciberacontecimento. IN: NAKAGAWA, Regiane; SILVA, Alexandre (Orgs). Semiótica da Comunicação II. São Paulo: INTERCOM, 2015.

HENN, Ronaldo; PILZ, Jonas \& KOLINSKI MACHADO, Felipe. Celebração do casamento igualitário e homofobia nas redes digitais: \#lovewins na disputa de sentidos oriundos da apropriação da Havaianas. E-compós (Brasília), v. 21, p. ID 1400-0, 2018.

HENN, Ronaldo; MACHADO, Felipe \& GONZATTI, Christian. Todos nascemos nus e o resto é drag: performatividade dos corpos construídos em sites de redes sociais. Revista Intercom - RBCC (São Paulo, Online), vol. 42, n. 3, p. 201-220, set-dez 2019.

JANOTTI JÚNIOR, Jeder. À procura da batida perfeita: a importância do gênero musical para a análise da música popular massiva. Revista Eco-Pós. Rio de Janeiro. Pós-Graduação em Comunicação e Cultura. UFRJ. Vol. 6, n. 2, 2003, p. 31-46. Disponível em: <https://tinyurl.com/yy7edx3b> Acesso em 19 mar 2019.

JANOTTI JÚNIOR, Jeder et al. "F**K YOU ROGER, PLAY THE SONGS": rock, política e rasuras na turnê de Roger Waters no Brasil em 2018. In: XXVIII Encontro Anual da Compós, Pontifícia Universidade Católica do Rio Grande do Sul, 2019, Porto Alegre. Anais do XXVIII Encontro Anual da Compós, 2019.

LAKE, Marilyn. The Independence of Women and the Brotherhood of Man: Debates in the Labour Movement over Equal Pay and Motherhood Endowment in the 1920s. Labour History, vol. 63, 1992. Disponível em: <https://www.jstor.org/stable/27509136> Acesso em 13 mar 2019.

MALESSA, Francine \& ESMITIZ, Franciele. Novas identidades e performances feministas nos Sites de Redes Sociais através do coletivo midiático Think Olga. In: XIX Congresso de Ciências Da Comunicação Na Região Sul, 2018, Cascavel. Anais XIX Congresso de Ciências Da Comunicação Na Região Sul, 2018.

MEDEIROS, Beatriz \& POLIVANOV, Beatriz. "Tolerância zero para abusadores": ruptura de performance e criação de ambiente online por afiliação a partir do caso da banda PWR BTTM. Revista Animus, vol. 18, n. 38, pp. 37-56, 2019.

NUNES, Caroline \& SILVEIRA, Fabrício. Tensões identitárias nas cenas musicais de Porto Alegre. Cachorro Grande e o rock gaúcho. Cadernos da Escola de Comunicação, vol. 1, n. 13, pp. 49-62, 2015. Disponível em: <https://tinyurl.com/y2ldjkv7> Acesso em 18 mar 2019.

OLIVEIRA, Felipe Moura; OSORIO, Moreno \& HENN, Ronaldo. Agir cartográfico: proposta teóricometodológica para compreensão e exercício do jornalismo em rede. In: XXVI Encontro Anual da Associação Nacional dos Programas de Pós-graduação em Comunicação (Compós), 2019, Porto Alegre. Anais do XXVI Encontro Nacional da Compós, 2019.

OKIN, Susan. Gênero, o público e o privado. Revista de Estudos Feministas, vol. 16, n. 2, 2008. Disponível em: <https://tinyurl.com/y4bd72eu> Acesso em 18 mar 2019.

PEREIRA DE SÁ, Simone \& POLIVANOV, Beatriz. Auto-reflexividade, coerência expressiva e performance como categorias para análise dos sites de redes sociais. Revista Contemporânea,

Dossiê A Música e suas Determinações Materiais - https://revistaecopos.eco.ufrj.br/

ISSN 2175-8689 - v. 23, n. 1, 2020

DOI: 10.29146/eco-pos.v23i1.27551 
Salvador, vol. 10, n. 3, pp. 574-596, 2012. Disponível em: <http://twixar.me/45sK> Acesso em 13 mar 2019.

PEREIRA DE SÁ, Simone \& JANOTTI JÚNIOR, Jeder. Revisitando a noção de gênero musical em tempos de cultura musical digital. XXVII Encontro Anual da Compós: Belo Horizonte, 2018. Disponível em <http://twixar.me/h5sK> Acesso em 19 mar 2019.

PILZ, Jonas. A ressignificação do ciberacontecimento pela publicidade: Os sentidos oriundos da apropriação de \#meuamigosecreto pela Universal Pictures do Brasil no Facebook. In: XVII Congresso de Ciências da Comunicação na Região Sul, 2016, Curitiba. Anais do XVII Congresso de Ciências da Comunicação na Região Sul, 2016. Disponível em: <http://www.portalintercom.org.br/anais/sul2016/resumos/R50-1112-1.pdf> Último acesso em 2019.

POLIVANOV, Beatriz. Dinâmicas identitárias em sites de redes sociais: estudo com participantes de cenas de música eletrônica no Facebook. Rio de Janeiro: Multifoco, 2014.

POLIVANOV, Beatriz \& CARRERA, Fernanda. Rupturas performáticas em sites de redes sociais: um olhar sobre fissuras no processo de apresentação de si a partir de e para além de Goffman. Intexto (UFRGS. Online), 2019. Disponível em:<http://twixar.me/W5sK> Acesso em 06 mar 2019.

QUÉRÉ, Louis. Entre facto e sentido: a dualidade do acontecimento. Trajectos - Revista de Comunicação, Cultura e Educação, Lisboa, n. 6, p. 59-76, 2005.

SIBILIA, Paula. Autenticidade e performance: a construção de si como personagem visível. Revista Fronteiras - estudos midiáticos, vol. 17, n. 3, set-dez de 2015. Disponível em:< http://twixar.me/05sK> Acesso em 03 mar 2019.

TAYLOR, Charles. Sources of the self. Cambridge: Cambridge University Press, 1989.

VALENZUELA, Sebastián. Analisando o uso de redes sociais para o comportamento de protesto: o papel da informação, da expressão de opiniões e do ativismo. Revista Compolítica, n. 4, vol. 1, pp. 13-52, 2014. Disponível em: <https://tinyurl.com/y47tco6v> Acesso em 13 mar 2019.

WEBER, Jéssica. Redes sociais amplificam vozes feministas, mas o quanto a luta pela igualdade de gênero avançou?. Zero Hora, Porto Alegre, 1 de set de 2017. Disponível em: <http://twixar.me/15sK>. Acesso em 20 mar 2019. 